\title{
Significance of the board-certified surgeon systems and clinical practice guideline adherence to surgical treatment of esophageal cancer in Japan: a questionnaire survey of departments registered in the National Clinical Database
}

\author{
Yasushi Toh ${ }^{1}\left[\right.$. Hiroyuki Yamamoto ${ }^{2} \cdot$ Hiroaki Miyata ${ }^{2} \cdot$ Mitsukazu Gotoh $^{3} \cdot$ Masayuki Watanabe $^{1}$. \\ Hisahiro Matsubara ${ }^{1} \cdot$ Yoshihiro Kakeji $^{3} \cdot$ Yasuyuki Seto $^{3}$
}

Received: 22 December 2018 / Accepted: 7 April 2019 / Published online: 12 April 2019

(c) The Author(s) 2019

\begin{abstract}
Background It remains unknown how much institutional medical structure and process of implementation of clinical practice guidelines for esophageal cancers can improve quality of surgical outcome in Japan.

Methods A web-based questionnaire survey was performed for departments registered in the National Clinical Database in Japan from October 2014 to January 2015. Quality indicators (QIs) including structure and process indicators (clinical practice guideline adherence) were evaluated on the risk-adjusted odds ratio for operative mortality (AOR) of the patients using registered cases in the database who underwent esophagectomy and reconstruction in 2013 and 2014.

Results Among 916 departments which registered at least one esophagectomy case during the study period, 454 departments (49.6\%) responded to the questionnaire. Analyses of 6661 cases revealed that two structure QIs (certification of training hospitals by Japan Esophageal Society and presence of board-certified esophageal surgeons) were associated with significantly lower AOR $(p<0.001$ and $p=0.005$, respectively). One highly recommended process QI regarding preoperative chemotherapy had strong tendency to associate with lower AOR $(p=0.053)$. In two process QIs, the answer "performed at the doctor's discretion" showed a significant negative impact on prognosis, suggesting importance of institutional uniformity. Conclusions The medical institutional structure of board-certified training sites for esophageal surgeons and of participation of board-certified esophageal surgeons improves surgical outcome in Japan. Establishment of appropriate QIs and their uniform implementation would be crucial for future quality improvement of medical care in esophagectomy.
\end{abstract}

Keywords Esophageal cancer · Esophagectomy · Quality indicator · Board-certified surgeon · Questionnaire survey

\section{Abbreviations \\ NCD National Clinical Database \\ AOR Risk-adjusted odds ratio for operative mortality \\ JSS Japan Surgical Society \\ JSGS Japanese Society of Gastroenterological Surgery}

Yasushi Toh and Hiroyuki Yamamoto equally contributed to this work.

Mitsukazu Gotoh

mgotoh@fmu.ac.jp

The Japan Esophageal Society, Tokyo, Japan

2 National Clinical Database, Tokyo, Japan

3 The Japanese Society of Gastroenterological Surgery, 3-1-17 Axior Mita 6F, Minato-ku, Tokyo 108-0073, Japan
JES Japan Esophageal Society

QI Quality indicator

\section{Introduction}

Quality of care is measured by "the degree to which health services for individuals and populations increase the likelihood of the desired health outcomes and are consistent with current professional knowledge" (Institute of Medicine: http://www.nationalacademies.org/hmd/). In recent years, while many clinical practice guidelines have been developed for the management of cancer in Japan, the evidence-practice gap, i.e., incomplete utilization or dissemination of current clinical knowledge in clinical practice, remains a problem $[1,2]$. The first measure to resolve this problem 
is to try to understand the medical care system, such as the appropriate distribution of health professionals and equipment in clinical settings, and the status of implementation of clinical practice guidelines for various cancers (evaluation of structure and process in the Donabedian model [3]) using established quality indicators (QIs) throughout Japan and to compare them with indicators of the level of medical care, such as the incidence of complications, treatmentrelated mortality, and survival rate. Differences in the results between each institution and the whole country are required to be fed back to the relevant institution as individual treatment outcomes to make the quality of medical care uniform across institutions in Japan, and for future reconsideration of clinical practice guidelines and standards of care.

The National Clinical Database (NCD) is a registry of surgical cases established in 2010 by 10 academic societies that are affiliated to the board-certified surgeon system [4], including the Japan Surgical Society (JSS) and the Japanese Society of Gastroenterological Surgery (JSGS) and consists of a network of more than 5,000 participating institutions and more than 1,02,000 departments throughout Japan as of August 2018. More than 95\% of cases of surgeries performed in Japan are registered in the NCD [5]. In the field of gastroenterological surgery, detailed data on 8 major surgical procedures have been collected to prepare a risk model for each surgical procedure, which is utilized as a risk calculator for risk evaluations in clinical settings [6-13].

In cooperation with a study group, "a study on the utilization of high-accuracy organ cancer registration in clinical practice guidelines and medical specialist training," of the Health and Labour Sciences Research Grant, the NCD conducted a questionnaire survey of the significance of boardcertified surgeons in the treatment of various cancers (esophageal, gastric, colorectal, liver, pancreatic, biliary tract, lung and breast cancers) and the status of implementation of guidelines in each of the departments of institutions registered in the NCD in 2014. Although the results have been reported in part in Japanese [14], the influence of the surveyed items for each cancer on indicators of the level of medical care, such as the incidence of postoperative complications, treatment-related mortality, and survival rate, has not been analyzed in detail. In the present paper, we report the results exclusively related to esophageal cancer, which was among the first investigated.

\section{Materials and methods}

\section{Questionnaire survey}

A web questionnaire page was created on the NCD registration system, and the department responsible for esophageal surgery at each of the registered institutions was requested to answer the questionnaire. The survey period was from October 1, 2014 to January 31, 2015. Of all, 454 of total 916 departments (49.6\%) which registered at least one esophagectomy case in this period responded to the questionnaire. A total of 11,809 patients who underwent esophagectomy and reconstruction during this period in Japan were included in this study. The questionnaire items related to the treatment of esophageal cancer as QIs are shown in Table 1.

For questions (Q) 7-11, the respondents selected one of three responses: not performed in principle (group A), performed in principle (group B), and recommended by the institution, but performed at the doctor's discretion (group C).

Q7-Q11 were selected through discussion among council members of the Japan Esophageal Society (JES), mainly from those with higher recommendation grades in the 2012

Table 1 The questionnaire items related to the treatment of esophageal cancer

Q1 Is your institution accredited by or related to the Japan Surgical Society (JSS)?

Q2 Is your institution certified by the Japanese Society of Gastroenterological Surgery (JSGS)?

Q3 Is your institution certified by the Japan Esophageal Society (JES)?

Q4 Is there a board-certified gastroenterological surgeon by JSGS?

Q5 Is there a board-certified esophageal surgeon by JES?

Q6 Is there a board-certified esophagologist by JES?

Q7 Do you screen for synchronous head and neck cancer in new patients with esophageal cancer?

Q8 Do you administer steroids in the perioperative period to patients scheduled to undergo esophagectomy and reconstruction for esophageal cancer?

Q9 Do you perform lymph node dissection around the bilateral recurrent laryngeal nerves (\#101R, L, \#106recR, L: [25, 26]) during resection and reconstruction for thoracic esophageal cancer?

Q10 Do you administer neoadjuvant chemotherapy for resectable stage II/III (T1-3N0/1M0, Union for International Cancer Control [UICC] classification, 2002 edition) thoracic esophageal cancer?

Q11 Do you measure the serum level of carcinoembryonic antigen (CEA) or squamous cell carcinoma antigen (SCC) (or both) during followup after esophagectomy? 
Guidelines for Diagnosis and Treatment of Carcinoma of the Esophagus [15]. Actually, with regard to the medical care for esophageal cancer in Japan, it is often difficult to determine the grade of recommendation based on high-level evidence. Accordingly, the grades of recommendation were B (there is scientific evidence and it is recommended) for Q7-Q10 and $\mathrm{C} 1$ (there is no scientific evidence, but it is recommended) for $\mathrm{Q} 11$, and no questions with grade $\mathrm{A}$ recommendation (there is strong scientific evidence and it is strongly recommended), which was considered appropriate for the QIs, were selected.

\section{Relationships between the above QIs and the level of medical care}

Of the patients who underwent esophagectomy and reconstruction in 2013 or 2014 at the 454 departments that responded to the questionnaire, only those who did not refuse registration, had no missing data on their gender or outcome, and gave approval for participating in the survey were analyzed. Eventually, 6,661 (56.4\%) patients were analyzed (the number of patients before examining the questionnaire data: 11,809 patients) (Fig. 1). Association between the QIs and operative mortality was evaluated for these patients. Here, the operative mortality was defined as death within the index hospitalization period regardless of the length of hospital stay (up to 90 days), as well as any death after discharge, up to 30 days after surgery. In esophagectomy, 90-day mortality is thought to be a better outcome measure

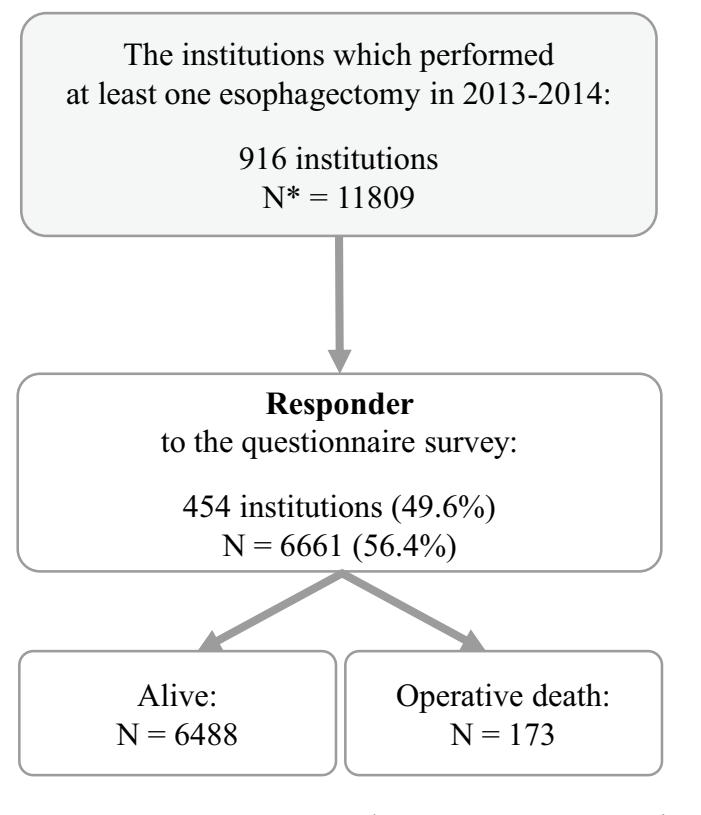

* : $\mathrm{N}$ means case number.

Fig. 1 The flow of patient selection because it provides a better understanding of true death risk for the surgeon and patient $[16,17]$.

\section{Multivariable regression analysis}

To clarify the relationship between the answer of each questionnaires and operative mortality, multivariable logistic regression models fitted with generalized estimating equation were utilized, considering clustering of patients by hospital levels. To adjust patient-level risk factors, the following variables, which were risk model variables in the previous report [6], were utilized: age category, sex, preoperative activity of daily life (ADL) (any assistance), chronic obstructive pulmonary disease (COPD), cancer metastasis/ relapse, weight loss, white blood cell (WBC) $<4500 / \mu 1$, platelet $<120,000 / \mu 1$, albumin $<3.5 \mathrm{~g} / \mathrm{dl}$, blood urea nitrogen $(\mathrm{BUN})<8 \mathrm{mg} / \mathrm{dl}$, Serum Na $<138 \mathrm{mEq} / \mathrm{l}$, and prothrombin time-international normalized ratio $(\mathrm{PT}-\mathrm{INR})>1.25$. The results were expressed as odds ratio (OR) and confidence interval (95\% CI). Q1, Q4 and Q11 did not proceed to multivariable analyses, because distribution of the variables was extremely low (<1\%, Q1 and Q4) (Table 2) and guideline recommendation grade was low (Q11).

\section{Statistical analysis}

Chi-square tests or Fisher's exact tests were performed to compare categorical data and their distributions as appropriate. Two-sided probability values less than 0.05 are considered to be statistically significant. All statistical calculations were performed with STATA 15 (STATA Corp., TX, USA).

\section{Results}

\section{The patient's characteristics, the response distribution and the relationship between each result of QIs and the crude operative mortality}

The patients' characteristics in this study and their relationships with crude operative mortality rates are shown in Table 3. Most of the risk model variables indicated in the previous report [6] showed statistically significant relationships with higher crude operative mortality rates.

The response distribution in each QI and relationship between each result of QIs and the crude operative mortality rates are shown in Table 2 . Three-hundred and eighty-nine $(45.9 \%)$ out of 847 institutions certified by JSGS as of 2014 and $98(86.7 \%)$ out of 113 institutions certified by JES as of 2014 responded to the questionnaire. In Qs1-6, the institutions which were accredited by or related to JSS (Q1) or certified by JES (Q3) and those with board-certified esophageal surgeon or esophagologist 
Table 2 The response distribution and relationship between each quality indicator and the crude operative mortality

\begin{tabular}{|c|c|c|c|c|c|c|c|c|}
\hline \multirow[t]{2}{*}{ Questionnaire item } & \multirow{2}{*}{$\begin{array}{l}\text { Depart- } \\
\text { ment } \\
\text { No. }\end{array}$} & \multicolumn{2}{|c|}{$\begin{array}{l}\text { Operative } \\
\text { death }(n=173)\end{array}$} & \multicolumn{2}{|c|}{$\begin{array}{l}\text { Alive } \\
(n=6488)\end{array}$} & \multicolumn{2}{|l|}{ Total } & \multirow[t]{2}{*}{ Mortality rate } \\
\hline & & Pt No. & $\%$ & Pt No. & $\%$ & No. & $\%$ & \\
\hline \multicolumn{8}{|c|}{ Q1 Institution accredited by or related to JSS } & $p=0.009 *$ \\
\hline No & 4 & 2 & 1.2 & 11 & 0.2 & 13 & 0.2 & $15.38 \%$ \\
\hline Accreditet & 410 & 165 & 95.4 & 6377 & 98.3 & 6542 & 98.2 & $2.52 \%$ \\
\hline Relater & 40 & 6 & 3.5 & 100 & 1.5 & 106 & 1.6 & $5.66 \%$ \\
\hline \multicolumn{8}{|l|}{ Q2 Institution certified by JSGS } & $p=0.375^{*}$ \\
\hline Yes & 389 & 166 & 96.0 & 6291 & 97.0 & 6457 & 96.9 & $2.57 \%$ \\
\hline No & 65 & 7 & 4.0 & 197 & 3.0 & 204 & 3.1 & $3.43 \%$ \\
\hline \multicolumn{8}{|l|}{ Q3 Institution certified by JES } & $p<0.001$ \\
\hline Yes & 98 & 81 & 46.8 & 4249 & 65.5 & 4330 & 65.0 & $1.87 \%$ \\
\hline No & 356 & 92 & 53.2 & 2239 & 34.5 & 2331 & 35.0 & $3.95 \%$ \\
\hline \multicolumn{8}{|c|}{ Q4 Board-certified gastroenterological surgeon by JSGS } & $p=1.000^{*}$ \\
\hline Yes & 440 & 172 & 99.4 & 6437 & 99.2 & 6609 & 99.2 & $2.60 \%$ \\
\hline No & 14 & 1 & 0.6 & 51 & 0.8 & 52 & 0.8 & $1.92 \%$ \\
\hline \multicolumn{8}{|c|}{ Q5 Board-certified esophageal surgeon by JES } & $p<0.001$ \\
\hline Yes & 95 & 84 & 48.6 & 4115 & 63.4 & 4199 & 63.0 & $2.00 \%$ \\
\hline No & 359 & 89 & 51.4 & 2373 & 36.6 & 2462 & 37.0 & $3.61 \%$ \\
\hline \multicolumn{8}{|c|}{ Q6 Board-certified esophagologist by JES } & $p=0.001$ \\
\hline Yes & 159 & 112 & 64.7 & 4913 & 75.7 & 5025 & 75.4 & $2.23 \%$ \\
\hline No & 295 & 61 & 35.3 & 1575 & 24.3 & 1636 & 24.6 & $3.72 \%$ \\
\hline \multicolumn{8}{|c|}{ Q7 Screen for synchronous head and neck cancer } & $p=0.005^{*}$ \\
\hline Not performed in principle & 39 & 5 & 2.9 & 307 & 4.7 & 312 & 4.7 & $1.60 \%$ \\
\hline Performed in principle & 325 & 145 & 83.8 & 5750 & 88.6 & 5895 & 88.5 & $2.46 \%$ \\
\hline Doctor's discretion $^{\mathrm{a}}$ & 90 & 23 & 13.3 & 431 & 6.6 & 454 & 6.8 & $5.07 \%$ \\
\hline \multicolumn{8}{|c|}{ Q8 Administer steroids in the perioperative period } & $p<0.001$ \\
\hline Not performed in principle & 215 & 63 & 36.4 & 2340 & 36.1 & 2403 & 36.1 & $2.62 \%$ \\
\hline Performed in principle & 178 & 87 & 50.3 & 3760 & 58.0 & 3847 & $57.8 \%$ & $2.26 \%$ \\
\hline Doctor's discretion $^{\mathrm{a}}$ & 61 & 23 & 13.3 & 388 & 6.0 & 411 & 6.2 & $5.60 \%$ \\
\hline \multicolumn{8}{|c|}{ Q9 Perform lymph node dissection around the bilateral recurrent laryngeal nerves } & $p=0.001 *$ \\
\hline Not performed in principle & 22 & 4 & 2.3 & 68 & 1.0 & 72 & 1.1 & $5.56 \%$ \\
\hline Performed in principle & 330 & 144 & 83.2 & 5962 & 91.9 & 6106 & 91.7 & $2.36 \%$ \\
\hline Doctor's discretion $^{\mathrm{a}}$ & 102 & 25 & 14.5 & 458 & 7.1 & 483 & 7.3 & $5.18 \%$ \\
\hline \multicolumn{8}{|c|}{$\begin{array}{l}\text { Q10 Administer neoadjuvant chemotherapy for resectable stage II/III thoracic esophageal } \\
\text { cancer }\end{array}$} & $p=0.029$ \\
\hline Not performed in principle & 53 & 18 & 10.4 & 379 & 5.8 & 397 & 6.0 & $4.53 \%$ \\
\hline Performed in principle & 308 & 133 & 76.9 & 5391 & 83.1 & 5524 & 82.9 & $2.41 \%$ \\
\hline Doctor's discretion $^{\mathrm{a}}$ & 93 & 22 & 12.7 & 718 & 11.1 & 740 & 11.1 & $2.97 \%$ \\
\hline
\end{tabular}

JSS Japan Surgical Society, JSGS Japanese Society of Gastroenterological Surgery (JSGS), JES Japan Esophageal Society

aDoctor's discretion indicates "recommended by the institution, but performed at the doctor's discretion"

*Fisher's exact test by JES (Q5 or Q6, respectively) showed significantly lower crude operative mortality rates. In 454 departments that responded to the questionnaire, the numbers of group B that answered "performed in principle" were $325(71.6 \%)$, $178(39.2 \%), 330(72.7 \%)$ and $308(67.8 \%)$ in QIs 7, 8, 9 and 10, respectively. Group B showed a significantly lower crude operative mortality in Q9 and Q10, while group C (performed at doctor's discretion) resulted in worse results in Q7 and Q8. Q11 was excluded from the analysis because of its low recommendation grade in the guidelines [15]. 
Table 3 Patients' characteristics and crude operative mortality rates

\begin{tabular}{|c|c|c|c|c|c|}
\hline \multirow[t]{2}{*}{ Variables } & \multicolumn{2}{|c|}{$\begin{array}{l}\text { Opera- } \\
\text { tive death } \\
(n=173)\end{array}$} & \multicolumn{2}{|c|}{$\begin{array}{l}\text { Alive } \\
(n=6488)\end{array}$} & \multirow[t]{2}{*}{$p$ value } \\
\hline & No. & $\%$ & No. & $\%$ & \\
\hline Age & & & & & $<0.001$ \\
\hline$\leq 59$ & 17 & 9.8 & 1261 & 18.9 & \\
\hline $60-64$ & 24 & 13.9 & 1194 & 17.9 & \\
\hline $65-69$ & 20 & 11.6 & 1531 & 23.0 & \\
\hline $70-74$ & 42 & 24.3 & 1421 & 21.3 & \\
\hline $75-79$ & 47 & 27.2 & 875 & 13.1 & \\
\hline$\geq 80$ & 23 & 13.3 & 379 & 5.7 & \\
\hline Male & 158 & 91.3 & 5592 & 84.0 & 0.007 \\
\hline Preoperative ADL (any assistance) & 13 & 7.5 & 147 & 2.2 & $<0.001$ \\
\hline COPD & 21 & 12.1 & 450 & 6.8 & 0.004 \\
\hline Weight loss $>10 \%$ & 36 & 20.8 & 516 & 7.7 & $<0.001$ \\
\hline Cancer metastasis/relapse & 3 & 1.7 & 59 & 0.9 & $0.197^{\circ}$ \\
\hline Platelet $<120,000 / \mu 1$ & 10 & 5.8 & 221 & 3.3 & 0.067 \\
\hline Albumin $<3.5 \mathrm{~g} / \mathrm{dl}$ & 62 & 35.8 & 911 & 13.7 & $<0.001$ \\
\hline $\mathrm{BUN}<8 \mathrm{mg} / \mathrm{dl}$ & 4 & 2.3 & 140 & 2.1 & $0.785^{\circ}$ \\
\hline Serum $\mathrm{Na}<138 \mathrm{mEq} / \mathrm{l}$ & 33 & 19.1 & 566 & 8.5 & $<0.001$ \\
\hline PT-INR $>1.25$ & 6 & 3.5 & 122 & 1.8 & $0.136^{\circ}$ \\
\hline $\mathrm{WBC}<4500 / \mu 1$ & 10 & 5.8 & 509 & 7.6 & 0.350 \\
\hline
\end{tabular}

$A D L$ activity of daily life, $C O P D$ chronic obstructive pulmonary disorder, $B U N$ blood urea nitrgen, $P T$-INR prothrombin time-international normalized ratio, $W B C$ white blood cell

${ }^{a}$ Fisher's exact test

\section{Relationship between the medical care system in relation to employment of board-certified surgeons at the department and the risk-adjusted odds ratio for operative mortality (AOR)}

The results after risk-adjustment using the factors mentioned in Materials and Methods are shown in Fig. 2. The numbers of the patients who showed operative death in the departments not accredited by or related to JSS and those in the departments without board-certified surgeons by JSGS were only $13(0.2 \%)$ and $52(0.8 \%)$, respectively. Therefore, neither Q1 nor Q4 proceeded to multivariable analyses.

1. Q2: There was no difference in the AOR between departments certified by JSGS $(n=389)$ and departments that were not $(n=65)$.

2. Q3, Q5 and Q6: The AOR was significantly lower in departments certified as training sites for esophageal surgeons by JES $(n=98)$ than in non-certified departments $(n=356)(p<0.001)$. The AOR was significantly lower in departments with board-certified esophageal surgeons $(n=95)$ than in those without board-certified esophageal surgeons $(n=359)(p=0.005)$. Similarly, there was a strong tendency that it was lower in departments with board-certified esophagologists $(n=159)$, which are a prerequisite for application for board-certified esophageal surgeons, than in those without $(n=295)$ $(p=0.050)$.

\section{Relationship between the rate of implementation of various QIs and the AOR}

Relationship between the rate of implementation of various QIs and the AOR is shown in Fig. 3. Q11 was not included because of its low level of recommendation in the guidelines.

1. Q7: Screening for synchronous head and neck cancer in new patients with esophageal cancer.

Groups A, B and C had 39, 325 and 90 departments, respectively, and most departments performed the screening. There was no difference of the AOR between groups $\mathrm{A}$ and $\mathrm{B}$, and the outcome was rather better in group A than in group $\mathrm{C}(p=0.04)$, suggesting that doctor's discretion might result in worse outcome as compared to no implementation of this QI.

2. Q8: Perioperative steroid administration in esophagectomy and reconstruction.

Groups A, B and C had 215, 178 and 61 departments, respectively, showing that while some departments administered steroids in the perioperative period, others did not. There was no difference in the AOR between groups $\mathrm{A}$ and $\mathrm{B}$, and the outcome was rather better in group A than in group $\mathrm{C}(p=0.03)$, suggesting the same condition as Q7 mentioned above.

3. Q9: Lymph node dissection around the bilateral recurrent laryngeal nerves.

Groups A, B and C had 22, 330 and 102 departments, respectively, revealing that systematic lymph node dissection has been widely used. There was no difference of the AOR between groups A, B and C.

4. Q10: Neoadjuvant chemotherapy for resectable stage II/ III thoracic esophageal cancer.

This QI is exclusively set on the basis of a randomized clinical trial performed in Japan [15]. Groups A, B and $\mathrm{C}$ had 53, 308 and 93 departments, respectively, indicating that many departments selected the standard of care. There was a strong tendency that the AOR of group B was better than that of group A $(p=0.053)$.

\section{Discussion}

At present, 7 years have passed since the start of registration of surgical cases in the NCD, and the NCD has grown to a large-scale database that could potentially fully represent the reality of surgery throughout Japan $[4,5]$. The JSGS has 
Fig. 2 Relationship between board certification systems of surgeons and institution and the AOR in esophagectomy and reconstruction in Japan. The results show point estimates of odds ratio and $95 \%$ confidence intervals. JSGS Japanese Society of Gastroenterological Surgery, JES Japan Esophageal Society
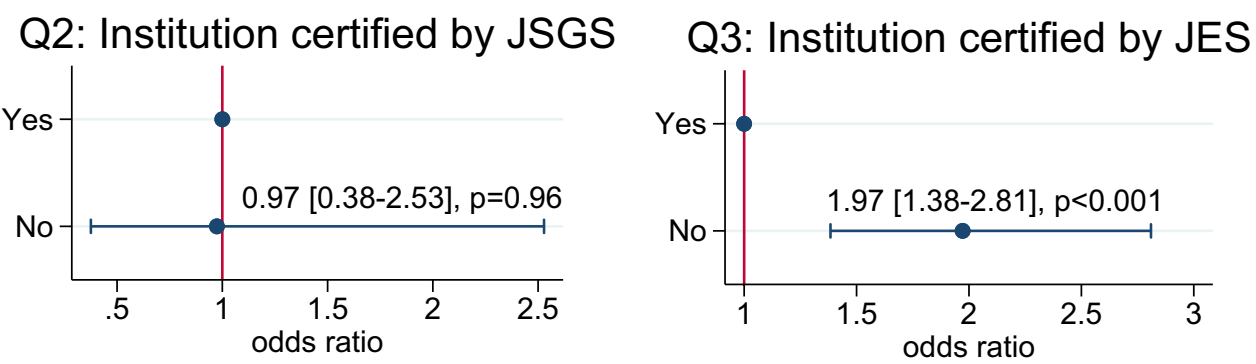

\section{Q5: Board-certified esophageal surgeon by JES}
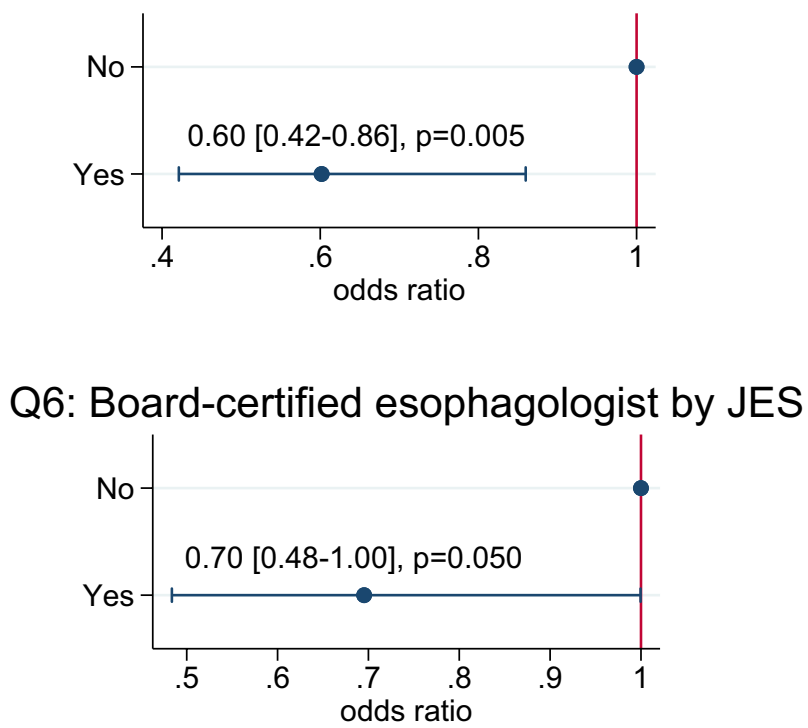

actively conducted research in various fields using these data $[6-13,18]$. In the future, it would be desirable to attempt to evaluate the quality of medical care on a nationwide scale using structure indicator benchmarks, such as the institution system, regarding the provision of medical services, and process indicator benchmarks, such as the status of implementation of the standard of care. This study was planned and conducted as a pilot project for the above objectives for esophageal, gastric, colorectal, liver, biliary tract, pancreatic, lung and breast cancer, using data obtained from a questionnaire survey of departments registered in the NCD in 2014 and surgical case data in 2013 and 2014 from the departments that responded to the questionnaire. As the first report, this paper reports the actual status of surgical treatment of esophageal cancer in Japan, the significance of board certification of surgeons and departments, and 5 process indicators related to esophagectomy and reconstruction.

\section{Significance of board certification of surgeons and institutions}

Konno et al. [19] reported that participation of gastroenterological surgeons who were board certified by the
JSGS contributed to favorable operative mortality after eight gastroenterological procedures mentioned before in Japan and that the number of board-certified surgeons in gastroenterological surgery per hospital could be a surrogate marker of operative mortality. We examined the relationship of the board certification of surgeons and institutions related to esophagectomy and reconstruction by the JSS, JSGS and JES to the operative mortality as an indicator of the level of medical care. The relationship concerning JSS could not be accurately assessed, because most of the departments that responded to the questionnaire belonged to institutions that were accredited by or related to JSS. However, the results suggested that the board certification of institutions as training sites for esophageal surgeons by JES and the presence of board-certified esophageal surgeons significantly reduced the AOR (Fig. 2). Furthermore, there was a strong tendency that the presence of board-certified esophagologists by JES, which is a prerequisite for the board-certified esophageal surgeons, showed a better AOR (Fig. 1). The NCD, JSGS and JES have begun to jointly investigate the significance of board-certified esophageal surgeons using larger-scale NCD data. 
Fig. 3 Relationship between process indicators related to esophagectomy and reconstruction and the AOR in Japan. The results show point estimates of odds ratio and $95 \%$ confidence intervals. Asterisk doctor's discretion indicates "recommended by the institution, but performed at the doctor's discretion"
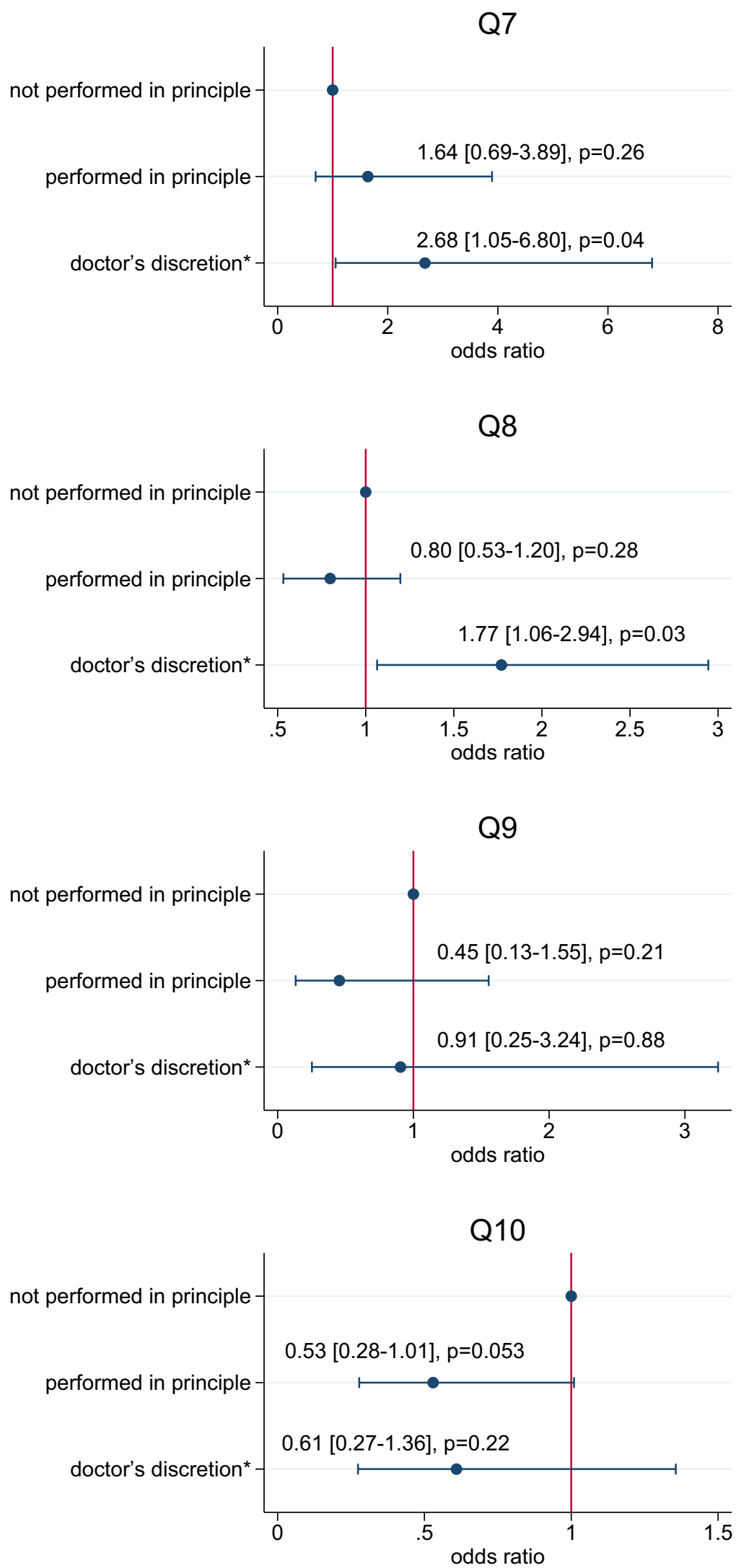


\section{Five process indicators related to esophagectomy and reconstruction}

General clinicians have not been fully aware of the significance of evaluation of the quality of medical care based on the measurement of a small number of QIs in clinical settings. This questionnaire survey was conducted to improve their understanding.

Because the QIs related to the surgical treatment of esophageal cancer used in this study did not necessarily have high grades of recommendation according to the 2012 Guidelines for Diagnosis and Treatment of Carcinoma of the Esophagus [15], which was the latest guideline when the survey was conducted in 2014, the measurement of these QIs may have a limited significance. Ideally only those QIs should have been selected whose implementation would be an indicator of a high quality of medical care. However, there are not many health services that can be highly recommended based on evidence not only at the time of the questionnaire survey, but even in the current surgical treatment of esophageal cancer (the 2017 Guidelines for Diagnosis and Treatment of Carcinoma of the Esophagus [20, 21]). Therefore, for the present study, a discussion was held among the council members of the JES to select 5 QIs that would be useful to enlighten general clinicians about the significance of QI measurement.

This study revealed that a considerable part of departments executed clinical practices recommended by the guidelines in Japan (Table 2). On the other hand, it was somewhat surprising that the AOR rates in departments in which doctor's discretion was permitted might be rather worse than in those which did not perform the QIs 7 and 8 in principle. This fact might indicate that, in the field of esophageal surgery like an esophagectomy, establishing and nationwide standardization of high levels of evidences would yield much improvement of a quality of medical care. Contrarily, regarding Q10 which is based on one of the best evidences in Japan even at present [15], there was a strong tendency that group B showed the lower operative mortality rates as compared to group A, suggesting that departments performing a standard therapy might achieve better short-term outcomes. In the future, it needs to be evaluated whether an improvement in the rate of implementation over time through significant QI selection and feedback of results actually leads to an eventual improvement in the level of medical care including a quality of life and ADL [22, 23].

\section{Limitations of this study}

The first limitation of this study was that it was based on a questionnaire survey. Since any users who had been registered in the NCD as a user and obtained an ID could answer the questionnaire, the questionnaire data may not necessarily reflect the opinions of the departments. The second limitation is that the questionnaire response rate was $49.6 \%$, suggesting that the results do not fully reflect the actual situation in the entire country. However, considering the fact that 95\% of esophagectomy and reconstruction cases throughout Japan are registered in the NCD [5] and that most of the departments that responded to the questionnaire were accredited by or related to the JSS and nearly $87 \%$ of institutions responded were certified by JES (98 out of 113 as of 2014), it is possible that the results reflected the actual status of surgical treatment of esophageal cancer throughout Japan to some extent. In this questionnaire survey, the response rate of high volume centers tended to be higher than that of low volume centers (data not shown), suggesting a possibility that the effect of each QI might be underestimated. The third limitation was that, as described above, the grounds for selecting the QIs were not clear. In the future, QIs need to be selected using a method like the Delphi method and their appropriateness evaluated [24].

\section{Conclusions}

In this study, we investigated the relationship of the medical care system in relation to esophageal surgery and the status of implementation of the selected QIs to the operative mortality in each department, through conducting a questionnaire survey of the departments registered in the NCD. The results suggested that the board certification of institutions as training sites for esophageal surgeons and the presence of board-certified esophageal surgeons at departments performing the treatment are associated with reduced operative mortality rates. Through activities like this, it is desirable to raise the awareness of the significance of objective evaluation of the quality of surgical treatment for esophageal cancer in clinical settings. In the future, we propose to report the results of questionnaire surveys conducted to evaluate the status of management of also other gastrointestinal cancers (gastric, colorectal, pancreatic, liver and biliary tract cancer).

Acknowledgements The authors thank all departments and societies related to the NCD for their participation to this study. This study was conducted as a part of "a study on the utilization of high-accuracy organ cancer registration in clinical practice guidelines and medical specialist training," supported by the Health and Labour Sciences Research Grant (Clinical Cancer Research) to M. Gotoh. We also thank Drs. M. Mori, K. Sugihara, K. Hirata, M. Nagino, Y. Kitagawa, T. Ohta, H. Konno, T. Sobue, A. Nashimoto, K. Kotake, N. Kokudo, M. Yamamoto, M. Tanaka, T. Shimosegawa, M. Sato and H. Tokuda for their cooperation.

Author contributions YT, HY and MG: planning of the study and writing. YT, HY, HM and MG: data analysis. MW, HM, YK and YS: discussion and advices. 
Funding This work was supported by a grant from the Ministry of Health, Labour and Welfare of Japan (201221064A) and by a grant from Japan Society for the Promotion of Science (16K10437, 19K09111).

\section{Compliance with ethical standards}

Ethical Statement All procedures were in accordance with the ethical standards of the responsible committee on human experimentation and with the Helsinki Declaration of 1964 and later versions.

Conflict of interest Hiroaki Miyata and Hiroyuki Yamamoto are affiliated with the Department of Healthcare Quality Assessment at the University of Tokyo. The department is a social collaboration department supported by grants from the National Clinical Database, Johnson \& Johnson K.K., and Nipro Co. Other authors declare that they have no potential conflicts of interest in this manuscript.

Open Access This article is distributed under the terms of the Creative Commons Attribution 4.0 International License (http://creativeco mmons.org/licenses/by/4.0/), which permits unrestricted use, distribution, and reproduction in any medium, provided you give appropriate credit to the original author(s) and the source, provide a link to the Creative Commons license, and indicate if changes were made.

\section{References}

1. Nakayama T, Imanaka Y, Okuno Y, et al. Analysis of the evidence-practice gap to facilitate proper medical care for the elderly: investigation, using databases, of utilization measures for National Database of Health Insurance Claims and Specific Health Checkups of Japan (NDB). Environ Health Prev Med. 2017;22:51.

2. Grol R, Grimshaw J. From best evidence to best practice: effective implementation of change in patients' care. Lancet. 2003;362:1225-30.

3. Donabedian A. Evaluating the quality of medical care. Milbank Mem Fund Q. 1966;44(Suppl):166-206.

4. Miyata $\mathrm{H}$, Gotoh $\mathrm{M}, \mathrm{Hashimoto} \mathrm{H}$, et al. Challenges and prospects of a clinical database linked to the board certification system. Surg Today. 2014;44:1991-9.

5. Gotoh M, Miyata H, Hashimoto H, et al. National Clinical Database feedback implementation for quality improvement of cancer treatment in Japan: from good to great through transparency. Surg Today. 2016;46:38-47.

6. Takeuchi H, Miyata $\mathrm{H}$, Gotoh $\mathrm{M}$, et al. A risk model for esophagectomy using data of 5354 patients included in a Japanese nationwide web-based database. Ann Surg. 2014;260:259-66.

7. Kurita N, Miyata H, Gotoh M, et al. Risk Model for distal gastrectomy when treating gastric cancer on the basis of data from 33,917 Japanese patients collected using a nationwide web-based data entry system. Ann Surg. 2015;262:295-303.

8. Watanabe M, Miyata H, Gotoh M, et al. Total gastrectomy risk model: data from 20,011 Japanese patients in a nationwide internet-based database. Ann Surg. 2014;260:1034-9.

9. Kobayashi H, Miyata H, Gotoh M, et al. Risk model for right hemicolectomy based on 19,070 Japanese patients in the National Clinical Database. J Gastroenterol. 2014;49:1047-55.

10. Matsubara N, Miyata H, Gotoh M, et al. Mortality after common rectal surgery in Japan: a study on low anterior resection from a newly established nationwide large-scale clinical database. Dis Colon Rectum. 2014;57:1075-81.
11. Kenjo A, Miyata H, Gotoh M, et al. Risk stratification of 7,732 hepatectomy cases in 2011 from the National Clinical Database for Japan. J Am Coll Surg. 2014;218:412-22.

12. Kimura W, Miyata H, Gotoh M, et al. A pancreaticoduodenectomy risk model derived from 8575 cases from a national single-race population (Japanese) using a web-based data entry system: the 30-day and in-hospital mortality rates for pancreaticoduodenectomy. Ann Surg. 2014;259:773-80.

13. Nakagoe T, Miyata H, Gotoh M, et al. Surgical risk model for acute diffuse peritonitis based on a Japanese nationwide database: an initial report on the surgical and 30-day mortality. Surg Today. 2015;45:1233-43.

14. Takahashi AHN, Miyata H, Ono M, Gotoh M, Iwanaka T. A detailed report looked through a large clinical registry; how they enter the data; how they carry their practice. Geka. 2016;78:285-97.

15. Kuwano H, Nishimura Y, Oyama T, et al. Guidelines for diagnosis and treatment of carcinoma of the esophagus April 2012 edited by the Japan Esophageal Society. Esophagus. 2015;12:1-30.

16. Walters DM, McMurry TL, Isbell JM, Stukenborg GJ, Kozower BD. Understanding mortality as a quality indicator after esophagectomy. Ann Thorac Surg. 2014;98:506-11.

17. Talsma AK, Lingsma HF, Steyerberg EW, Wijnhoven BP, Van Lanschot JJ. The 30-day versus in-hospital and 90-day mortality after esophagectomy as indicators for quality of care. Ann Surg. 2014;260:267-73.

18. Kakeji $\mathrm{Y}$, Takahashi A, Udagawa $\mathrm{H}$, et al. Surgical outcomes in gastroenterological surgery in Japan: report of National Clinical database 2011-2016. Ann Gastroenterol Surg. 2018;2:37-54.

19. Konno H, Kamiya K, Kikuchi H, et al. Association between the participation of board-certified surgeons in gastroenterological surgery and operative mortality after eight gastroenterological procedures. Surg Today. 2017;47:611-8.

20. Kitagawa Y, Uno T, Oyama T, et al. Esophageal cancer practice guidelines 2017 edited by the Japan Esophageal Society: part 1. Esophagus. 2018;25:25. https://doi.org/10.1007/s1038 8-018-0641-9.

21. Kitagawa Y, Uno T, Oyama T, et al. Esophageal cancer practice guidelines 2017 edited by the Japan esophageal society: part 2. Esophagus. 2018;25:25. https://doi.org/10.1007/s1038 8-018-0642-8.

22. Haj Mohammad N, De Rooij S, Hulshof M, et al. Activities of daily living and quality of life during treatment with neoadjuvant chemoradiotherapy and after surgery in patients with esophageal cancer. J Surg Oncol. 2016;114:684-90.

23. Tatematsu N, Hasegawa S, Tanaka E, Sakai Y, Tsuboyama T. Impact of oesophagectomy on physical fitness and health-related quality of life in patients with oesophageal cancer. Eur J Cancer Care. 2013;22:308-13.

24. Higashi T, Nakamura F, Saruki N, Sobue T. Establishing a quality measurement system for cancer care in Japan. Jpn J Clin Oncol. 2013;43:225-32.

25. Japan Esophageal Society. Japanese Classification of Esophageal Cancer, 11th edition: part I. Esophagus. 2017;14:1-36.

26. Japan Esophageal Society. Japanese Classification of Esophageal Cancer, 11th edition: part II and III. Esophagus. 2017;14:37-65.

Publisher's Note Springer Nature remains neutral with regard to jurisdictional claims in published maps and institutional affiliations. 